\title{
Conhecimento, Inovação e Competência em Organizações Financeiras: uma Análise sob o Ponto de Vista de Gestores deBancos
}

\author{
Marcel Ginotti Pires \\ Reynaldo Cavalheiro Marcondes
}

\begin{abstract}
Resumo
Este artigo trata o conhecimento, a inovação e as competências essenciais como elementos fundamentais para se buscar a melhoria da competitividade no setor bancário. Está apoiado em pesquisa exploratória qualitativa em que foram entrevistados sete executivos da cúpula de diferentes grandes bancos que operam no país. Foram realizadas entrevistas em profundidade e os dados foram tratados com técnicas da análise de conteúdo. Os resultados encontrados mostram o seguinte: o conhecimento não é objeto de gestão e a ênfase é dada à manipulação de dados sobre os clientes, sem se considerarem as oportunidades efetivas de aprendizado; a inovação não se configura como essencial para a sobrevivência dos bancos estudados, pois não é vista como vantagem competitiva sustentável, devido a que as práticas de imitação são corriqueiras; as competências essenciais são um conceito claro para os executivos entrevistados, mas eles não têm clareza quanto a como conectálas com as competências individuais, além do que são favoráveis mais à sua aquisição externa do que ao desenvolvimento delas internamente.
\end{abstract}

Palavras-chaves: competências essenciais; tecnologia da informação; conhecimento; inovação; bancos.

\begin{abstract}
This paper shows the knowledge, the innovation, and the core competencies as essential elements to reach the improvement of the competitivity in the bank industry. It is based on qualitative exploratory research in which seven high executives of different large banks that operate in the country were interviewed. These interviews were in depth interviews, and the data gathered were handled with techniques of the content analysis. The results found show the following: knowledge is not an object of management, and the emphasis is given to client data handling, not considering the effective opportunities of learning; innovation is essential for the studied banks survival, because it is not seen as a sustainable competitive advantage due to the constant imitation practices; core competencies are a clear concept for the interviewed executives, but they are not sure about how to connect them to the individual competencies; besides they are favorable rather to their external acquisition than to their inner development.
\end{abstract}

Key words: core competencies; information technology; knowledge; innovation; banks. 


\section{INTRODUÇÃO}

Este artigo trata da identificação da contribuição do conhecimento, particularmente aquele relativo ao cliente, da inovação de produtos financeiros e das competências essenciais existentes nos bancos, no enfrentamento da elevada competição típica deste segmento.

A evolução tecnológica propiciou as condições necessárias para a transição de uma economia industrial para uma economia de informação, na qual, cada vez mais, o conhecimento representa o elemento diferenciador e estratégico presente nas economias modernas, culminando com o uso crescente das tecnologias da informação e da comunicação.

Durante tal evolução vários termos e conceitos surgiram e se disseminaram amplamente no mercado, dos quais alguns se destacam, particularmente os referentes à "era do conhecimento". Essa denominação reflete a crescente importância do conhecimento e de sua utilização para o progresso econômico das nações, sendo um de seus ativos mais importantes.

Evidenciando a relevância que a inovação assume na era do conhecimento, alguns autores (Nonaka e Takeuchi, 1997) destacam que é necessária uma nova teoria de criação do conhecimento organizacional para explicá-la. Deve-se ressaltar também que, embora este trabalho não enfoque especificamente a tecnologia da informação (TI), deixar de abordá-la, ainda que de maneira pouco profunda, seria incorreto, porquanto, como asseveram McGee e Prusak (1994, p.18), nas instituições financeiras os "orçamentos referentes à tecnologia de informação representam a maior parcela dos investimentos de capital”. No Brasil o setor bancário se apresenta como o segundo setor em participação no PIB nacional, além de caracterizar-se como grande usuário das tecnologias da informação. Davenport e Prusak (1998, p. 3) afirmam que "os bancos representam organizações que dependem fortemente dos dados”.

Destaca-se ainda que as diversas dimensões abordadas neste trabalho, relacionadas ao conhecimento e às competências, apresentam duas perspectivas: individual e organizacional. As duas se diferenciam no escopo em que subsistem, estando ainda fortemente relacionadas aos processos de aprendizagem que, de maneira análoga, existem nas esferas individual e organizacional. Essas, contudo, não serão objeto de discussão neste artigo cujo foco está na perspectiva organizacional, tanto em relação ao conhecimento quanto às competências. Convém destacar que, embora as competências individuais possam ser 
consideradas como competências essenciais de uma organização (Guimarães et al., 2001), isto não foi manifestado ou enfatizado em nenhum momento pelos gestores entrevistados, que não associaram a competência individual de seus funcionários como competência essencial em suas organizações, conforme definição de Prahalad e Hammel (1990). Assim, quando a dimensão abordada se referir a um escopo individual, ela será destacada. Além disso, não se pretende, neste artigo, aprofundar a discussão sobre a relação existente entre competências individuais e organizacionais.

Tendo em vista as considerações e justificativas apresentadas, foi definido como objetivo principal deste artigo identificar os enfoques e as práticas dos bancos para tornarem-se competitivos, utilizando-se do conhecimento, da inovação de seus produtos e das competências essenciais neles existentes, sob o ponto de vista de altos executivos. Como objetivo específico pretende-se identificar a importância da TI no trato desses três elementos.

\section{Referencial Teórico}

\section{Conhecimento}

O conhecimento pessoal pode ser compreendido como "uma mistura fluida de experiência condensada, valores, informação contextual e insight experimentado, a qual proporciona uma estrutura para a avaliação e incorporação de novas experiências e informações” (Davenport e Prusak, 1998, p. 6). Ele é valioso, pois está próximo da ação, constituindo-se também na "informação mais valiosa e, conseqüentemente, mais difícil de gerenciar. É valiosa precisamente porque alguém deu à informação um contexto, um significado, uma interpretação" (Davenport e Prusak, 1998, p. 19).

O conhecimento pode conduzir a níveis superiores no desenvolvimento e produção de bens e serviços. Nesse sentido, o conhecimento organizacional pode ser o fundamento de uma vantagem competitiva sustentável para a organização (Davenport e Prusak, 1998), vantagem essa compreendida como a obtenção de “desempenho superior” (McGee e Prusak, 1994, p. 26) de uma organização sobre suas demais concorrentes.

Polanyi $(1959,1983)$ desenvolveu uma teoria do conhecimento humano em que, além de avaliar os processos mentais que conduzem à sua criação, propõe a sua divisão em dois tipos distintos, denominados de tácito e explícito. Essa divisão se constitui em uma referência na literatura de criação e gestão do conhecimento 
e se tem difundido desde a sua apresentação. Polanyi (1959) afirma que aquilo que usualmente é descrito como conhecimento, tais como palavras escritas ou fórmulas matemáticas, compreende somente um tipo, denominado de explícito. O outro tipo seria o não formulado ou tácito (aquele que é compreendido sem ser expresso diretamente), considerado como o princípio dominante de todo o conhecimento.

Nonaka e Takeuchi (1997) enfatizaram a criação do conhecimento organizacional. Fizeram isto entendendo que o ponto fundamental da organização corresponde à "busca por processos contínuos de inovação", pois isto permite a criação de novos conhecimentos. Ao conceituarem-no, esses autores consideraram necessário destacar três aspectos envolvidos: (1) ele se refere a crenças e compromissos, sendo função de uma atitude, perspectiva ou intenção específica; (2) ele está relacionado à ação, ou seja, é sempre o conhecimento "com algum fim”, argumento este também referendado por Davenport e Prusak (1998, p. 7), que destacam que a sua importância está no fato de ele estar próximo da ação, isto é, "ele pode e deve ser avaliado pelas decisões ou tomadas de decisões às quais ele leva”; e (3) ele se refere ao significado, sendo específico ao contexto e relacional.

Deve-se atentar, contudo, que as considerações de Nonaka e Takeuchi (1997) e Davenport e Prusak (1998) sobre a relação entre o conhecimento individual e a ação não podem ser compreendidas como equivalentes à competência individual. Zarifian (2001) descreve competência individual como a competência do indivíduo (e não a qualificação do emprego), que é avaliada na sua utilização em situações profissionais, na relação prática do indivíduo com a situação profissional. Esse mesmo autor define competência como "entendimento prático de situações que se apóiam em conhecimentos adquiridos e os transformam na medida em que aumenta a diversidade das situações” (Zarifian, 2001, p. 72).

A teoria baseada em recursos (resource-based theory) pressupõe a definição do conhecimento organizacional como um dos componentes das competências distintivas de uma organização, pois ele é percebido como fonte fundamental para a obtenção de retornos acima da média (Spender, 1996; McEvily, 2000). Alguns autores sugerem que as vantagens baseadas no conhecimento são difíceis de ser imitadas, quando as razões para o desempenho superior de uma empresa sobre os seus concorrentes não podem ser controladas ou identificadas (Diericky e Cool, 1989). Isso é também conhecido como ambigüidade causal.

Mas quais fatores poderiam ser associados à criação de um desempenho superior da empresa? McEvily (2000) argumenta que tal desempenho superior é conseqüência do conhecimento organizacional único da empresa sobre como 
organizar as atividades produtivas, transformar recursos físicos e combiná-los em necessidades específicas dos clientes.

\section{Inovação}

Neste artigo, a definição de inovação utilizada será aquela descrita por Roberts (1988), que a compreende como a geração de uma idéia ou invenção e a conversão desta invenção em algum negócio ou aplicação útil.

A inovação pode ocorrer de várias maneiras. Ela pode ser incremental ou radical (Roberts, 1988; Leifer et al., 2000); representar modificações de entidades já existentes ou criação de novas; pode ser incorporada em produtos, serviços ou processos; orientada por meio do uso pelos consumidores, pela indústria ou pelo governo; baseada em múltiplas tecnologias ou em apenas uma única tecnologia (Roberts, 1988). Além disso, ela varia tanto em relação aos seus tipos quanto em relação às suas fontes, segundo Von Hippel (1988). Esse autor destaca que as inovações podem ser oriundas dos usuários, clientes, fornecedores, enfim de uma ampla rede de relacionamentos que envolvem a organização. Ele propõe que a utilidade da inovação deve ser analisada sob a perspectiva dos lucros temporários acima da média (economic rents) que ela pode proporcionar. Finalmente, a inovação pode ser de novos produtos ou serviços; novas tecnologias de processos produtivos; novas estruturas ou sistemas administrativos e mesmo um plano ou programa pertencentes aos membros da organização (Damanpour, 1991).

Um dos aspectos da inovação tecnológica, aquele relacionado à informação, foi destacado por Porter e Millar (1985), que afirmaram que a TI poderia modificar as regras da competição, por meio da mudança da natureza da competição na indústria, incluindo a bancária; da geração de novos negócios e do fato de que ela pode ser considerada uma alavanca que as companhias poderiam usar para criar vantagem competitiva, pois afetariam suas atividades de valor. A TI também ofereceria a perspectiva de criação de novos negócios baseados na tecnologia, podendo propiciar uma vantagem competitiva por meio de gestão cuidadosa dos elos de ligação entre as organizações.

Pennings e Harianto (1992) desenvolveram trabalhos de pesquisa em bancos, e examinaram as práticas destas organizações na adoção de inovações tecnológicas. Esses autores conceituaram inovação como a recombinação qualitativa de know-how residente nos ativos humanos e de capital da organização, representando a adoção de novas idéias, processos, produtos ou serviços que podem ser desenvolvidos internamente ou adquiridos externamente. A inovação 
é o resultado das habilidades e capacidades que vêm sendo acumuladas no tempo e cujo estoque pode ser utilizado para a alavancagem estratégica de mudanças, mas limitadas pela direção e ajuste dos esforços organizacionais (Pennings e Harianto, 1992).

Alguns autores (Von Krogh, Ichijo e Nonaka, 2000) destacam que a criação do conhecimento é a mais importante fonte de inovação em qualquer organização, e que parece existir forte relação entre inovação e conhecimento tácito, sendo que, em geral, este tipo de conhecimento representa a sua fonte de vantagem competitiva. Drucker (1998) afirma que o banco moderno representa uma das mais potentes inovações baseadas no conhecimento.

Também é notório o fato de que, no mercado financeiro, o acesso fácil das organizações às informações torna as vantagens competitivas baseadas na diferenciação e na inovação fugazes, porque as inovações de produtos são facilmente imitadas pelos competidores (Grant, 1991).

\section{CompetênciasEssenciais}

Após um período em que foi enfatizada a análise das características da indústria e a posição da organização em contexto competitivo, modelo este que tem em Porter (1980) um de seus principais representantes, a década de 80 presenciou o desenvolvimento de novas alternativas de posicionamento estratégico, tais como a teoria dos recursos (Vasconcelos e Cyrino, 1999). Sob a perspectiva desta teoria, o foco da análise foi deslocado para os fatores produtivos internos à organização e para a maneira pela qual estes fatores contribuíam para a criação de valor dentro dela por meio de seus recursos e competências. Essa abordagem disseminou-se particularmente após o trabalho de Wernerfelt (1984), que analisa a organização sob uma perspectiva de recursos, tanto daqueles que ela possui, quanto daqueles que precisam ser desenvolvidos. No trabalho desse autor, também são feitas analogias entre as barreiras de entrada e as denominadas barreiras de posições de recursos.

Os recursos da organização, conforme manifestado por Barney (1991), constituem todos os ativos, capacidades, processos organizacionais, atributos da organização, informação, conhecimento etc., que são controlados por uma organização, e que lhe permitem conceber e implementar estratégias que desenvolvam a sua eficiência e a sua efetividade. Barney (1991) destaca que, apesar de os recursos da organização serem heterogêneos e imóveis, podem constituir fontes de vantagens competitivas sustentáveis. Para que isto aconteça, entretanto, os recursos da organização devem possuir alguns atributos que precisam ser valiosos, raros, difíceis de imitar e para os quais não devem existir 
substitutos equivalentes. Contudo a definição de sustentabilidade de Barney (1991) depende da possibilidade ou impossibilidade de duplicação competitiva.

Uma premissa fundamental da teoria baseada em recursos é que as competências organizacionais, também denominadas de recursos por alguns autores (Barney, 1991; Barney, Fuerst e Mata, 1995), que são heterogêneas e imóveis, formam a base da vantagem competitiva sustentável (Lado e Wilson, 1994; Barney, Fuerst e Mata, 1995).

Em 1995, Barney, Fuerst e Mata desenvolveram um estudo sobre as relações entre a TI e a possibilidade de ela criar uma vantagem competitiva sustentável para a organização. Esses autores concluíram que não é exatamente a TI que iria possibilitar tal condição, mas um conjunto de fatores que, presentes, permitiriam que as organizações atingissem esse estágio. Dos fatores avaliados, consideram que somente as habilidades administrativas de TI seriam capazes de criar uma sustentabilidade, isto é, conceber, desenvolver e explorar aplicações dessa tecnologia para apoiar e ampliar outras funções de negócios.

Diversos autores (Diericky e Cool, 1989; Barney, 1991; Collis e Montgomery, 1995; McEvily, 2000) destacam o fato de que a dificuldade de imitabilidade e de substituição dos recursos da organização contribui para a manutenção de retornos acima da média e, conseqüentemente, de suas vantagens competitivas, podendo tornar-se fonte durável dessas vantagens, se tais recursos forem bem protegidos. Além disso, McEvily e Chakravarthy (2002) destacam que o conhecimento pode criar barreiras à imitação, estando tais barreiras parcialmente localizadas nos recursos da organização, conforme demonstrado pela teoria dos recursos.

Ainda na década de 90, a discussão das competências organizacionais e das capacidades dinâmicas ampliou-se, por meio de um novo conceito que passou a ser identificado como a teoria da competição baseada nas competências ou teoria das capacidades dinâmicas, em que se busca uma teoria de formação das competências organizacionais (Mintzberg, 2000; Vasconcelos e Cyrino, 2000). Essa teoria destaca que a concorrência passa a ser fundada sobre as competências que estão baseadas nos recursos únicos e raros da organização (Vasconcelos e Cyrino, 1999).

Cada vez mais o conhecimento é percebido como fundamental para a competência organizacional (Sanchez e Heene, 1997), e foi definido por Sanchez, Heene e Thomas (1996) como a habilidade para sustentar o desenvolvimento coordenado de ativos e capacidades, de maneira a permitir o auxílio para que a organização alcance seus objetivos. 


\section{Procedimentos Metodológicos}

Este artigo está fundamentado em uma pesquisa exploratória qualitativa, por não se dispor ainda de uma sistematização de teorias e conhecimentos desenvolvidos em conformidade com os objetivos do estudo. Nesse caso, não se trabalhou com a correlação entre as variáveis conhecimento, inovação e competência essencial, mas com a sua caracterização qualitativa, dado o interesse principal em conhecer como elas são percebidas e tratadas no ambiente dos bancos (Köche, 1997).

Foram entrevistados sete executivos de cinco grandes bancos, sendo quatro diretores e três gerentes seniores que ocupavam cargos imediatamente abaixo da diretoria. A duração das entrevistas variou entre uma hora e vinte minutos até duas horas e trinta minutos. Dos bancos incluídos na pesquisa, quatro são bancos de varejo e um deles é especificado como banco de atacado. Os de varejo são dois bancos estatais, o Banco Nossa Caixa e a Caixa Econômica Federal. Os bancos privados são o Itaú e o Unibanco, tidos como de varejo, e o Lloyds TSB Bank, que é banco de atacado.

Todas as entrevistas seguiram um roteiro único previamente definido, com perguntas abertas, cujas respostas foram gravadas em fita de áudio e transcritas ipsis litteris para que não se perdesse nenhum detalhe dos depoimentos. O produto das entrevistas foi tratado de maneira a resultar significativo e válido para a análise, conforme recomendação de Bardin (1977). O tratamento dos dados foi realizado por meio da aplicação das técnicas de análise de conteúdo, em que se procedeu à codificação e categorização de todo o material transcrito.

Vários são os critérios de categorização que podem ser utilizados na análise de conteúdo. Os critérios utilizados neste trabalho foram: (1) semântico, referente à categoria temática, que é a "contagem de um ou vários temas ou itens de significação, numa unidade de codificação previamente determinada" (Bardin, 1977, p. 77), e em que se determinam "núcleos de sentido" (Bardin, 1977, p. 105); (2) sintático, relacionado aos verbos, adjetivos e substantivos (estes últimos não foram analisados neste trabalho), ou seja, as palavras plenas, aquelas que são “portadoras de sentido” (Bardin, 1977, p. 82); e (3) léxico, que é a classificação das palavras segundo o seu sentido, com emparelhamento dos sinônimos e dos sentidos próximos.

Somente após a conclusão de cada fase da análise, respectivamente sintática, léxica, semântica e posteriormente a categorização, é que se avançou para a fase seguinte. A última delas, correspondente à identificação das novas categorias, 
foi realizada pela manipulação concomitante dos conjuntos relacionados nos quadros léxicos e semânticos para cada questão, conduzindo à síntese apresentada a seguir.

\section{ANÁLISE E INTERPRETAÇÃo dAs ENTREVISTAS}

As pesquisas de mercado para aumentar o nível do conhecimento dos clientes foram citadas com freqüência, o que parece revelar a existência de necessidades comuns entre os bancos da amostra sobre este aspecto. Todos eles as fazem continuadamente, seja para detectar níveis de satisfação dos clientes, como para identificar as necessidades e os desejos que o público apresenta. De certa forma, isto evidencia a percepção de que os bancos estão permanentemente tentando antecipar-se às ações da concorrência, desenvolvendo ações internas e externas. As ações internas são apoiadas na análise de suas bases de dados, enquanto as ações externas são apoiadas pelas pesquisas de mercado, ou ainda, conforme o gestor do Banco Lloyds argumentou, por meio de uma "inteligência de mercado". Essas ações têm fornecido os requisitos necessários para a inovação nos produtos financeiros e/ou nos seus processos, indo, conforme o executivo do Unibanco, em "busca de diferenciais competitivos".

Particularmente em relação ao conhecimento relativo ao cliente, um dos focos do estudo, verificou-se certa disparidade nos níveis de conhecimento existentes entre bancos públicos e privados. Embora seja unânime a importância que todos os executivos atribuem à necessidade de se conhecer o cliente da instituição financeira, algumas delas não têm conseguido transformar esse conhecimento em produtos. A deficiência no conhecimento relativo ao cliente dificulta a inovação, pois este corresponde a um dos elementos centrais das competências que permitem retornos acima da média do mercado, conforme defendido por Davenport e Prusak (1998), Grover e Davenport (2001), entre outros.

Ainda em relação aos clientes, os executivos entrevistados destacaram que a preocupação não se restringe somente a satisfazer as suas necessidades imediatas, mas também permitir que os bancos se antecipem aos desejos de seus clientes, expressos ou não, como forma de oferecerem novos e/ou melhores alternativas à sua clientela. Para isso entendem que é preciso buscar atuações mais pró-ativas em relação ao mercado e à concorrência, desenvolvendo produtos que possam ser absorvidos pelo público alvo. Esse tipo de abordagem, contudo, está se dando muito mais com base no uso cada vez maior das tecnologias de informação. 
Busca-se na inovação a criação de um valor novo para o cliente, não necessariamente associado a novos produtos. Para os entrevistados, inovar não significa apresentar algo absolutamente novo, mas oferecer diferenciais de valor para o cliente, corroborando os conceitos de Porter (1985) e Drucker (1998). Para os executivos dos bancos estudados parece que as inovações têm sido incrementais e têm origens principalmente externas, no ambiente dos negócios financeiros, na concorrência e nos clientes, tendo alguns executivos deixado claro que as grandes ou radicais inovações dificilmente poderiam ocorrer inesperada ou isoladamente neste segmento.

A inovação, entretanto, também poderia estar ocorrendo de modo pulverizado em pequenas ou incrementais inovações e isto poderia propiciar vantagem competitiva, embora todos tenham a percepção de que esta vantagem no segmento bancário é ainda menos duradoura, conforme aponta Grant (1991). Além disso, existem os riscos envolvidos nas operações bancárias, pois a falta de maior conhecimento pode conduzir a organização a lançar produtos que não satisfaçam o cliente, ou pior, que em vez de atender às suas expectativas, possam incorrer em falhas que afetem a sua confiança na credibilidade do banco.

Apesar da inovação ser considerada essencial por Roberts (1998) e Drucker (1999), que afirmam ser ela a única maneira de se obter vantagem competitiva em relação à concorrência, constatou-se haver ambigüidade entre os executivos. Eles ressaltaram a sua importância, mas divergiram sobre a ênfase que deve ser dada a ela pelas organizações. As opiniões dos entrevistados, contudo, coincidem com as afirmações feitas por Grant (1991) e Collis e Montgomery (1995). Os riscos inerentes a essa postura, assumidos diferentemente por cada um dos bancos, provocam a distinção na ênfase que estes poderiam atribuir à inovação. As restrições impostas pela legislação foram consideradas relevantes.

Esses executivos foram unânimes em destacar a necessidade de se manter acompanhamento permanente dos movimentos dos bancos concorrentes, inclusive no mercado internacional. Eles citaram textualmente a monitoração das movimentações da concorrência como atitude indispensável e permanente estímulo à aprendizagem.

Em relação às dificuldades da inovação, foi destacado o elevado custo envolvido no desenvolvimento e lançamentos de produtos financeiros. Além disso, fatores como o pouco conhecimento dos clientes e a própria maneira de atuação da organização influenciam muito nos custos.

Embora custos, rentabilidade e retorno não tenham sido enfatizados neste estudo, os executivos freqüentemente destacaram que não é desejável dissociar a busca pelo lucro da preocupação como a inovação, corroborando as opiniões 
de Von Hippel (1988) e de Collis e Montgomery (1995). Interessa muito mais conhecer o que cada produto pode gerar de retorno para a organização, e efetivamente obtê-lo, do que a sua origem, se foi interno à organização ou copiado do mercado.

A percepção da rapidez com que os produtos são copiados no mercado foi outro elemento comum apontado pelos executivos. Práticas citadas anteriormente como as pesquisas e o acompanhamento de mercado favorecem essa situação, além do fato de que eles reconhecem que os bancos precisam oferecer o mesmo conjunto de produtos disponibilizados pela concorrência. Dessa forma, a busca pelo “diferencial competitivo" é marcada por certa alternância no lançamento de produtos pelos concorrentes, que utilizam, como no caso dos bancos estatais, vantagens que algumas vezes não podem ser reproduzidas pela concorrência. Por um lado, isto têm gerado vantagens de atuação para os bancos estatais, pois lhes permite ter acesso a recursos e vantagens operacionais junto às empresas do Estado, como a administração pública direta e com os chamados "serviços delegados do governo", expressão utilizada pelo executivo da Nossa Caixa. Por outro lado, eles destacaram as dificuldades operacionais causadas pela condição de ser estatal, o que torna as decisões sempre mais morosas, quando comparadas às dos bancos privados, pois todos os processos são regidos por legislação específica e própria que orienta o relacionamento dessas instituições com o mercado.

Com relação à importância da inovação, vista como o resultado do empenho da direção da empresa e dos seus funcionários, em que se busca "suscitar a inovação contínua", o executivo do Unibanco manifestou que "todos podem estar contribuindo para a inovação". Na mesma linha de percepção o executivo da Caixa Econômica Federal reforçou a preocupação com a disseminação da busca pela inovação, afirmando que "é preciso transferir esse processo de inovação da alta administração para toda a organização”. Já o executivo do Lloyds Banck manifestou ser necessário "reforçar justamente a parte criativa do produto" oferecido por aquele banco.

Em relação à diferenciação, citada como um dos dois elementos centrais de estratégia das organizações (Porter, 1985), é oportuno destacar o fato de que, apesar de os executivos considerarem difícil a inovação no segmento bancário, procuram desenvolver estratégias que criem no mercado elementos de diferenciação.

Os executivos enfatizaram a ação de fatores externos e internos à organização como influenciadores da inovação de produtos financeiros. Entre os diversos fatores externos destacaram o acompanhamento e monitoração da concorrência como sendo elemento de grande importância, permitindo avaliação permanente 
da atuação das demais instituições, de modo a propiciar capacidade de resposta mais rápida. As pesquisas de mercado e a busca pela identificação de oportunidades reforçam a percepção da necessidade de se analisar a concorrência. Em relação aos fatores internos, os executivos citaram a cultura organizacional, a ação da alta administração, as competências individuais e a busca do conhecimento relativo ao cliente como elementos mais significativos.

O valor da cultura organizacional (Barney, 1986) foi mais destacado pelos executivos dos bancos privados como elemento de grande relevância para suas organizações desenvolverem processos de inovação contínua e, portanto, como fator significativo para a obtenção de vantagem competitiva. Isso corrobora a teoria dos recursos (Barney, 1991; Collis e Montgomery, 1995; Hall, 1997), que destaca a influência que a cultura organizacional exerce no desempenho das organizações.

A ação da alta administração e a conseqüente qualidade do gestor foram também destacadas pelos executivos por representarem recursos-chaves na organização para a obtenção de vantagens competitivas.

As considerações feitas pelos entrevistados sobre as competências essenciais das suas instituições evidenciaram estarem atentos ao mercado. Para eles, oferecer os produtos disponibilizados pela concorrência é considerado fundamental para a aquisição da vantagem competitiva do negócio. Eles entendem que uma organização, ainda que não se destaque em termos de inovação, deve estar apta e ser capaz de empreender ações pró-ativas e/ou reagir rapidamente à oferta de produtos inovadores pelos seus concorrentes. Um ponto mencionado com freqüência foi a associação entre competência essencial e diferenciação. A diferenciação, nesse caso, também é considerada como a oferta de produtos ou serviços que não estão sendo oferecidos por outras instituições, mesmo que isto signifique apenas "custo inferior àquele oferecido pela concorrência", mesmo não tendo estes nenhum novo atributo diferenciador, conforme a manifestação do executivo do Lloyds TSB Bank.

A percepção do aumento da concorrência foi também um dos pontos de destaque nas preocupações dos executivos. Praticamente todos eles ressaltaram a presente situação do mercado nacional, embora as condições de desenvolvimento de competências em bancos públicos e em privados sejam, sob alguns aspectos, distintas. Os executivos da Nossa Caixa e do Unibanco destacaram que o aumento da concorrência tem sido benéfico para os clientes, pois está exigindo dos bancos maior dinamismo e maior atenção à satisfação de suas necessidades, assim como a melhoria nos produtos ofertados por eles. Essa situação também foi atribuída ao fato de que alguns bancos nacionais acabaram adquirindo conhecimento e, 
conseqüentemente, competências para atuarem naqueles segmentos que antes eram praticamente exclusivos dos bancos com atuação internacional.

A entrada de novos concorrentes, principalmente estrangeiros, tem preocupado os executivos entrevistados, pois estas instituições possuem capacidade de alavancar recursos no mercado internacional a um custo inferior àqueles obtidos pelas instituições financeiras nacionais. Eles destacam ainda que alguns bancos nacionais estão desenvolvendo significativa política de aquisições bancárias, ampliando, dessa forma, sua capacidade de atuação no mercado nacional e internacional. Foi destacado haver capacidade competitiva dos bancos nacionais perante as ameaças representadas pelos novos entrantes e pelos atuais concorrentes.

Especificamente, a TI é considerada relevante para a concepção de novos produtos. Essa posição foi mais enfatizada por um dos bancos privados, tendo o executivo afirmado ao entrevistador que todos os novos produtos da organização eram resultado do uso intensivo dos recursos da TI e da análise inicial da respectiva carteira de clientes. Para o executivo do Loyds Bank, que é banco de atacado, a TI é considerada apenas como recurso adicional e não necessariamente vital para o desenvolvimento dos seus negócios, ainda que a instituição tenha a preocupação de disponibilizar aos seus clientes as mais recentes tecnologias de informação existentes. Entretanto a TI permite a criação de produtos baseados puramente em tecnologia, evidenciando uma tendência de inovação que está associada de maneira crescente à sua aplicação em todas as operações bancárias.

Não obstante o valor da TI ser reconhecido pelos executivos, somente um deles enfatizou que ela tem sido utilizada para identificar oportunidades de negócios. Isso talvez esteja associado ao fato de que o seu banco implementa um conjunto de tecnologias especificas para a análise de suas bases de dados de clientes há mais tempo que os demais concorrentes. Pelo fato de ter adquirido maior experiência e eficiência nos trabalhos desenvolvidos, o banco consegue criar produtos direcionados aos clientes-alvo de maneira mais eficaz.

\section{Conclusões}

Embora o conhecimento seja considerado importante pelos executivos, não foi percebida preocupação com a sua gestão. Assim, a ênfase está sendo dada à manipulação das bases de dados sobre os clientes de modo a se manter e lançar novos produtos, mas não como oportunidade de aprendizado com o conhecimento acumulado. Nessa circunstância, corre-se o risco de se perder parte da memória 
e do aprendizado de determinados assuntos estratégicos. No caso dos bancos estatais, há ainda o agravante das restrições impostas pela legislação específica sobre suas operações.

Quanto à inovação no segmento bancário, apesar de ser algo relevante e importante, não se configura como essencial à sobrevivência dessas empresas, embora todos os bancos participantes do estudo tenham, em algum momento, lançado produtos ou processos novos ou mesmo uma solução inovadora incremental no mercado. Essa constatação não corrobora as afirmações de Porter (1997), Drucker (1998), Roberts (1998) e de vários autores identificados com as teorias dos recursos e das competências. A inovação não é percebida claramente como fator de diferenciação competitiva para os executivos, pois outros aspectos são tidos como mais relevantes, tais como a confiança e a conveniência que buscam proporcionar aos seus clientes. Além disso, também não se observou preocupação com investimentos na melhoria da capacidade de inovação naquelas instituições. As inovações são consideradas necessárias, mas os fatores organizacionais que poderiam facilitá-las não parecem estar sendo enfatizados. Os riscos presentes nas operações bancárias reforçam ainda mais a postura cautelosa observada nesse segmento.

Pode-se inferir que a prática de imitação, comum no segmento bancário, pode contribuir para a manutenção da competição entre as instituições, mas não lhes permite a obtenção de vantagens competitivas. Como praticamente não existem barreiras à imitação, torna-se ainda mais pertinente o conservadorismo demonstrado pelos executivos em relação aos riscos envolvidos em políticas de inovações. Além disso, e de modo distinto de outras indústrias, o produto financeiro criado não dispõe de mecanismos efetivos de proteção, tais como patentes ou marcas registradas, que possam garantir-lhe considerável nível de proteção intelectual contra a imitação nesse segmento.

Com relação às competências essenciais, os executivos têm presentes os conceitos enunciados por Hamel e Prahalad (1990) e por Sanchez e Heene (1997), mas as suas práticas não são congruentes com eles. Assim, consideram mais apropriado proceder à fusão ou aquisição de outras instituições como forma de adquirir, já prontas, algumas competências. Também não têm clareza quanto a como fazer a ligação entre as competências individuais e as essenciais.

$\mathrm{O}$ fato de essas instituições financeiras utilizarem grande agregado de tecnologias de informação em seus produtos disponíveis no mercado, não corrobora a afirmação de autores como Porter e Millar (1985) de que a tecnologia de informação poderia criar e sustentar vantagem competitiva. A TI pode criar alguma vantagem competitiva, mas parece ser incapaz de sustentá-la por períodos longos de tempo. 
Certamente a TI afeta a competitividade no segmento bancário, mas a diferenciação que poderia proporcionar está mais associada às habilidades que as organizações possuem no seu manuseio, como destacam Diericky e Cool (1989), Barney, Fuerst e Mata (1995) e Hall (1997). A tecnologia que os produtos financeiros agregam, representados principalmente pelos softwares, pode ser adquirida livremente no mercado e, com freqüência, as empresas que os comercializam oferecem serviços de suporte e consultoria. Como a implantação de novas tecnologias pode ser agilizada de maneira quase simultânea entre concorrentes, disponibilizando soluções muito similares para os clientes de bancos diferentes, a possibilidade de que tais recursos criem vantagens para qualquer um deles torna-se ainda mais reduzida.

Artigo recebido em 28.07.2003. Aprovado em 11.02.2004.

\section{REFERÊNCIAs BibLIOGRÁFICAS}

BARDIN, L.

Análise de conteúdo. Lisboa: Edições 70, 1977.

BARNEY, J. B.

Organizational culture: can it be a source of sustained competitive advantage? Academy of Management Review, v. 11, n. 3, p. 656, July 1986.

Firm resources and sustained competitive advantage. Journal of Management, v. 17, n. 1, p. 99-120, 1991.

BARNEY, J. B.;

FUERST, W. L.;

MATA, F. J.

Information technology and sustained competitive advantage: a resourcebased analysis. MIS Quarterly, Dec. 1995.
COLLIS, D. J.;

MONTGOMERY, C. A.

Competing on resources: strategy in the 1990s. Harvard Business Review, p.18-29, July/Aug. 1995.

DAMANPOUR, F.

Organizational innovation: a metaanalysis of effects of determinants and moderators. Academy of Management Journal, v. 34, n. 3, p. 555-590, 1991.

DAVENPORT, T. H.

Ecologia da informação: por que só a tecnologia não basta para o sucesso na era da informação. São Paulo: Futura, 1998.

DAVENPORT, T. H.; PRUSAK, L.

Conhecimento empresarial: como as organizações gerenciam o seu capital intelectual. Rio de Janeiro: Campus, 1998. 
DIERICKY, I.;

COOL, K.

Asset stock accumulation and sustainability of competitive advantage. Management Science, $\mathrm{v}$. 35, n. 12, Dec. 1989.

\section{DRUCKER, P.}

The discipline of innovation. Harvard Business Review, v. 76, n. 6, p. 149, Nov./Dec. 1998.

Desafios gerenciais para o século XXI. São Paulo: Pioneira, 1999.

\section{GOPALAKRISHNAN, S.;}

DAMANPOUR, F.

The impact of organizational context on innovation adoption in commercial banks. IEEE Transactions on Engineering Management, v. 47, n. 1, Feb. 2000.

\section{GRANT, R. M.}

The resource-based theory of competitive advantage: implications for strategy formulation. California Management Review, v. 33, n. 3, Spring 1991.

\section{GROVER, V.;}

DAVENPORT, T. H.

General perspective on knowledge management: fostering a research. Journal of Management Information Systems, v. 18, n. 1, p. 5-22, Summer 2001.

GUIMARÃES, T. DE A. et al.

Forecasting core competencies in a R\&D environment. R\&D Management, v. 31, n. 3, p. 249-256, July 2001.
HALL, R.

A framework linking intangible resources and capabilities to sustainable competitive advantage. Strategic Management Journal, v. 14, p. 607-619, 1993.

Complex systems, complex learning, and competence building. In: SANCHEZ, R.; HEENE, A. Strategic learning and knowledge management. New York: John Wiley \& Sons, 1997.

HAMEL, G.;

PRAHALAD, C. K.

Competindo pelo futuro. São Paulo: Campus, 1995.

HILL, C. W. L.;

MATUSIK, S. F.

The utilization of contingent work, knowledge creation, and competitive advantage. Academy of Management Review, v. 23, n. 4, p. 680-698, Oct. 1998.

KÖCHE, J. C.

Fundamentos da metodologia científica: teoria da ciência e prática da pesquisa. Rio de Janeiro: Vozes, 1997.

\section{LADO, A. A.;}

WILSON, M. C.

Human resource systems and sustained competitive advantage: a competency-based perspective. Academy of Management Review, v. 19, n. 4, p. 699-725, Oct. 1994.

LEIFER, R. et al.

Radical innovation: how mature companies can outsmart upstarts. Boston: Harvard Business School Press, 2000. 
MCEVILY, S. K.

Avoiding competence substitution through knowledge sharing. Academy of Management Review, v. 25, n. 2, p. 294-312, Apr. 2000.

MCEVILY, S. K.;

CHAKRAVARTHY, B.

The persistence of knowledge-based advantage: an empirical test for product performance and technological knowledge. Strategic Management Journal, v. 23, n. 4, p. 285-306, Apr. 2002.

MCGEE, J.;

PRUSAK, L.

Gerenciamento estratégico de informações. Rio de Janeiro: Campus, 1994.

MINTZBERG, H.

The rise and fall of strategic planning: reconceiving roles for planning, plans, planners. New York: Free Press, 1994.

NONAKA, I.;

TAKEUCHI, H.

Criação de conhecimento na empresa: como as empresas japonesas geram a dinâmica da inovação. Rio de Janeiro: Campus, 1997.

PENNINGS, J. M.;

HARIANTO, F.

The diffusion of technological innovation in the commercial banking industry. Strategic Management

Journal, v. 13, p. 29-46, 1992.

POLANYI, M.

The study of man. Chicago: the University of Chicago Press, 1959.
Tacit knowing. In: The tacit dimension. Gloucester: Peter Smith, 1983.

PORTER, M. E.

Competitive strategy: techniques for analyzing industries and competitors. New York: Free Press, 1980.

Competitive advantage: creating and sustaining superior performance. New York: Free Press, 1985.

Creating advantage. Executive Excellence, v. 14, n. 12, p. 17-19, Dec. 1997.

PORTER, M. E.;

MILLAR, V. E.

How information gives you competitive advantage. Harvard Business Review, p.149-161, July/Aug. 1985.

PRAHALAD, C. K.;

HAMEL, G.

The core competence of the organization. Harvard Business Review, May/June 1990.

ROBERTS, E. B.

Managing invention and innovation.

Research Technology Management, v. 31, n. 1, p. 11-30, Jan./Feb. 1988.

ROBERTS, R.

Managing innovation: the pursuit of competitive advantage and the design of innovation intense environments. Research Policy, v. 27, n. 2, p. 159176, June 1998.

SANCHEZ, R.; HEENE, A.

Strategic learning and knowledge management. New York: John Wiley \& Sons, 1997. 
SANCHEZ, R.;

HEENE, A.;

THOMAS, $\mathrm{H}$.

Towards the theory and practice of competence-based competition. In: Dynamics of competence-based competition: theory and practice in the new strategic management. Oxford: Elsevier, 1996.

\section{TEECE, D. J.}

Capturing value from knowledge assets: the new economy, markets for know-how, and intangible assets. California Management Review, v. 40, n. 3, p. 55-80, Spring 1998.

VASCONCELOS, F. C.;

CYRINO, A. B.

Vantagem competitiva: os modelos teóricos atuais e a convergência entre estratégia e teoria organizacional. Revista de Administração de Empresas, v. 40, n. 4, p. 20-37, out./ dez. 2000.
VON HIPPEL, E.

The sources of innovation. New York: Oxford University Press, 1988.

VON KROGH, G.;

ICHIJO, K.;

NONAKA, I.

Enabling knowledge creation: how to unlock the mystery of tacit knowledge and release the power of innovation. New York: Oxford University Press, 2000.

WERNERFELT, B.

A resource-based view of the firm. Strategic Management Journal, v. 5, n. 2, p. 171-181, Apr./June 84.

\section{ZARIFIAN, P.}

Objetivo competência: por uma nova lógica. São Paulo: Atlas, 2001. 